\title{
CERTIFICACION DE ORIGINALIDAD Y CESION DE DERECHOS DE AUTOR
}

Señores

\section{UNIVERSIDAD AUTÓNOMA DEL CARIBE}

\section{Revista PROSPECTIVA}

e-mail: rprospectiva@uac.edu.co,rprospectiva@gmail.com

Barranquilla, Colombia

REF:

Fecha: 20 de mayo de 2016

A los fines de certificar la originalidad y ceder los derechos de autor del artículo de la referencia,

Yo, Jimy Unfried Silgado

Residente en Barranquilla, Colombia

Filiación Institucional Universidad Autónoma del Caribe

Email: jimy.unfried@uac.edu.co

\section{Declaro:}

1. Que soy (somos) el (los) autor (es) y titular(es) de los derechos patrimoniales del artículo de la referencia.

2. Que ésta es una obra original conforme a la ley de propiedad intelectual de derechos de autor colombiana

3. Que el contenido del artículo de la referencia no ha sido publicado previamente y, que no se presentará a ningún otro medio de publicación en soporte escrito o electrónico antes de conocer la decisión del Comité Editorial de la Revista, en referencia a su posible publicación.

4. Que el firmante de esta certificación garantiza que el compromiso que aquí adquiere no infringe ningún tipo derechos de terceros.

5. Que la cesión de derechos incluye la autorización de su archivo electrónico y su adaptación, de ser necesario, para su incorporación en la red o en cualquier formato electrónico o base de datos, así como anexar los metadatos necesarios para realizar el registro de la obra, marcas de agua o cualquier otro sistema de seguridad o de protección.

6. Que la cesión de derechos incluye la reproducción en soportes digitales. Así como su distribución y la puesta a disposición a través de archivos institucionales a través de Internet, distribuir copias, y exhibirlo en Colombia y fuera del país, así como incluir el artículo en índices nacionales e internacionales.

7. Que el autor asume toda la responsabilidad, incluyendo las indemnizaciones por daños, que pudieran ejercitarse contra la Universidad Autónoma del Caribe por terceros que vieran infringidos sus derechos e intereses a causa de la cesión.

La Revista se obliga a respetar, en todo caso, los derechos morales del autor contenido en el artículo 30 de la Ley 23 de 1982, o cualquiera posterior a esta y pondrá el escrito del título de la referencia a disposición de los usuarios de la Revista para que hagan un uso legítimo de él, según lo permitido por la legislación aplicable, siempre que se cite su autoría, no se obtenga beneficio comercial, y no se realicen obras derivadas.

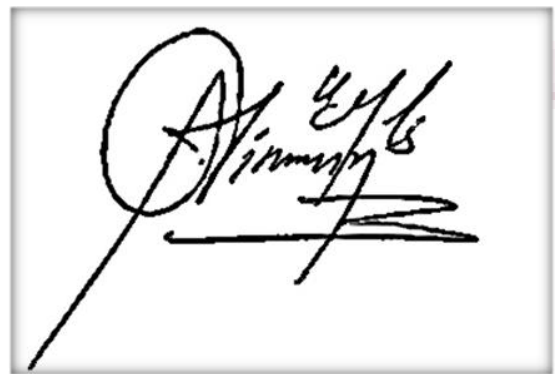

Firma de quien certifica y cede los derechos patrimoniales

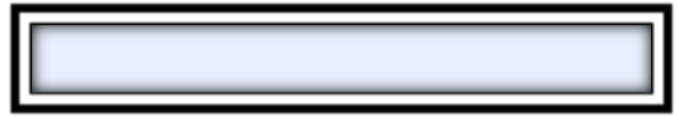

Firma de quien certifica y cede los derechos patrimoniales

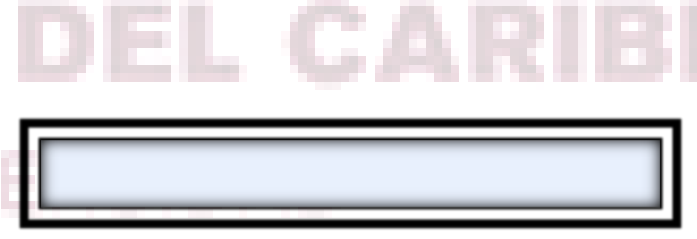

Firma de quien certifica y cede los derechos patrimoniales

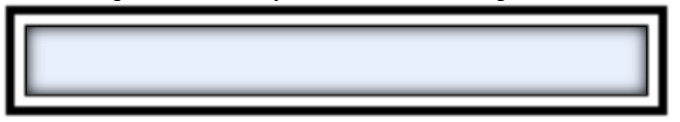

Firma de quien certifica y cede los derechos patrimoniales 